\title{
A suspicious calcium spike
}

Sergio García-Blas ${ }^{1 *}$, MD; Julio Núñez ${ }^{1}, \mathrm{MD}, \mathrm{PhD}$; Luis Mainar ${ }^{1}, \mathrm{MD}, \mathrm{PhD}$; Jaime Muñoz ${ }^{1}, \mathrm{MD}$;

Iván Martín ${ }^{1}$, MD; Alberto Domenech ${ }^{1}, \mathrm{MD}$; Antonio Guillen ${ }^{1}$, MD; Mariano Larman ${ }^{2}, \mathrm{MD}$;

Juan Sanchis ${ }^{1}, \mathrm{MD}, \mathrm{PhD}$

1. Cardiology Department, Hospital Clínico Universitario de Valencia, INCLIVA, Universitat de València, Valencia, Spain;

2. Department of Interventional Cardiology, Policlínica Gipuzkoa, San Sebastián, Spain

This paper also includes accompanying supplementary data published online at: http://www.pcronline.com/eurointervention/87th issue/94

An 82-year-old female with severe aortic stenosis was referred for transcatheter aortic valve replacement (TAVR). CT showed heavy calcification, especially in the junction of right coronary and noncoronary leaflets (Figure 1A), but no calcium in the outflow tract. Haemodynamic impairment occurred immediately after $26 \mathrm{~mm}$ Edwards SAPIEN XT ${ }^{\circledR}$ (Edwards Lifesciences, Irvine, CA, USA) prosthesis deployment (Moving image 1). Aortography showed contrast leak through the aortic annulus (Figure 1B, Moving image 2). The patient underwent urgent surgery, where bleeding partially contained by the epicardial fat and aortic wall haematoma were observed (Figure 1C). Aortic annulus rupture was located between the right coronary sinus and the non-coronary sinus (Figure 1D).

Risk factors for aortic annulus rupture include subannular calcification and prosthesis-annulus mismatch. Both were excluded in this case. However, prominent linear calcification described in
CT was located adjacent to the rupture area identified at surgery, which makes us hypothesise that this spike could be the cause of the annulus tear after prosthesis deployment. The fibrotic area under the non-coronary leaflet has been identified as prone to perivalvular leakage after aortic valve replacement due to its intrinsic weakness. This characteristic may also involve a higher risk of rupture in the presence of a high calcium burden in this area.

\section{Conflict of interest statement}

The authors have no conflicts of interest to declare.

\section{Online data supplement}

Moving image 1. $26 \mathrm{~mm}$ Edwards SAPIEN $\mathrm{XT}^{\circledR}$ prosthesis deployment.

Moving image 2. Aortography immediately after TAVR, showing contrast leak through the aortic annulus.

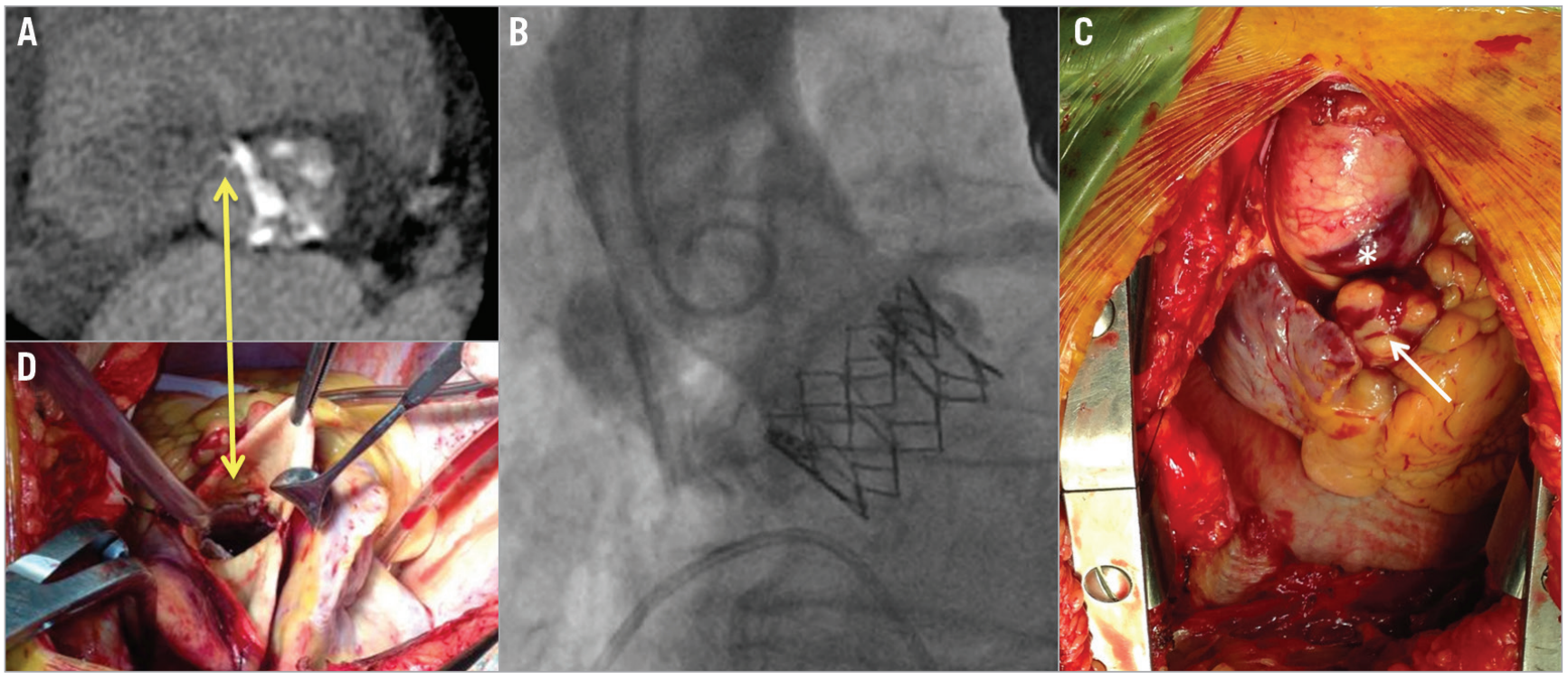

Figure 1. Preoperative CT, post-deployment aortography and surgical findings after aortic annulus rupture. A) Pre-procedural CT, calcium spike in the commissure between right coronary and non-coronary leaflets. B) Contrast leakage after prosthesis deployment. C) Surgery showed bleeding partially contained by the epicardial fat (arrow) and haematoma in the anterior aortic wall (asterisk). D) After prosthesis removal, a rupture area was identified between the right sinus and the non-coronary sinus (arrow).

*Corresponding author: Hospital Clínico Universitario de Valencia, Avda Blasco Ibañez 17, 46010 Valencia, Spain.

E-mail: sergiogarciablas@gmail.com 